\title{
Using DEMATEL Technique to Identify the Key Success Factors of Shared Decision-Making Based on Influential Network Relationship Perspective
}

\author{
Wen-Yi Liu, ${ }^{1,2,3}$ Tao-Hsin Tung, ${ }^{4}$ Yen-Ching Chuang $\mathbb{D}^{5}$ and Ching-Wen Chien $\mathbb{D}^{2}$ \\ ${ }^{1}$ Department of Health Policy Management, Bloomberg School of Public Health, Johns Hopkins University, Baltimore, MD, USA \\ ${ }^{2}$ Institute for Hospital Management, Tsing Hua University, Shenzhen Campus, Shenzhen, China \\ ${ }^{3}$ Shanghai Bluecross Medical Science Institute, Shanghai, China \\ ${ }^{4}$ Evidence-Based Medicine Center, Taizhou Hospital of Zhejiang Province Affiliated to Wenzhou Medical University, \\ Linhai 317000, China \\ ${ }^{5}$ Institute of Public Health \& Emergency Management, Taizhou University, Taizhou, China
}

Correspondence should be addressed to Yen-Ching Chuang; yenching.chuang@gmail.com and Ching-Wen Chien; ihhca@sz.tsinghua.edu.cn

Received 24 November 2020; Revised 4 March 2021; Accepted 29 March 2021; Published 21 April 2021

Academic Editor: Chi-Hua Chen

Copyright $\odot 2021$ Wen-Yi Liu et al. This is an open access article distributed under the Creative Commons Attribution License, which permits unrestricted use, distribution, and reproduction in any medium, provided the original work is properly cited.

In the field of medicine, shared decision-making (SDM) is an important issue primarily aimed at resolving the problem of information asymmetry between clinicians and patients in the selection of treatment options and follow-up nursing plans. Most previous studies on this topic have focused on key elements and the development and implementation of SDM scales. This study used the decision-making trial and evaluation laboratory (DEMATEL) method to establish a network of influence relationships among factors that are keys to the success of the SDM process. Survey data were obtained from a well-known brain hospital in China. The key factors of success included tailor information, flexibility approach, check understanding patient, document (discussion about) decision, present evidence, make or explicitly defer decision, and patient values and preferences. We determined that clinicians should provide a series of treatment options and follow-up care plans based on a patient's conditions and preferences. Clinicians should also actively communicate with patients and their families to ensure a thorough understanding of the entire treatment and nursing process. This study also highlights the academic value of the cross-disciplinary integration of medical decision issues and multiple attribute decision-making methodologies.

\section{Introduction}

Advances in medical technology have increased the number of treatment options, thereby necessitating the involvement of patients in shared decision-making (SDM) $[1,2]$. SDM is a patient-oriented approach to the selection of treatment options, emphasizing the need to consider the professional knowledge of clinicians within the context of patient values [3-5]. Considered best practice in terms of medical ethics, SDM is meant to reduce the problem of information asymmetry between clinicians and patients [6]. By bridging the gap between the priorities of clinicians and patients, SDM is also expected to improve drug compliance and patient satisfaction, well-being, and quality of life [7-10]. Clinicians tend to base decisions on medical knowledge and evidence, whereas patients consider the rigors of recovery and their quality of life.

Previous research on SDM can be divided into (1) key elements/features [11-13], (2) barriers and facilitators [14-16], and (3) SDM scales [17-21]. Identifying key factors of success is a multiple attribute decision-making (MADM) problem dealing with multiple criteria and the preferences of different decision-makers at the same time. Dolan [22] used the analytic hierarchy process (AHP) to improve communication between clinicians and patients in SDM. Dolan et al. [23] used an AHP-based decision model to analyse the 
screening priorities of patients. Those studies demonstrated the academic value of MADM in the context of medical care.

The AHP method is based on the assumption that relationships between attributes are independent; however, this is not necessarily consistent with actual operations $[24,25]$. Two methods have been developed to explore the relationship between attributes: interactive structural modelling (ISM) [26] and the decision-making trial and evaluation laboratory (DEMATEL) [27]. ISM uses 0 and 1 scales to construct an influence relationship network among attributes. Under this scheme, computation is simple; however, the information generated is sparce [28]. By contrast, DEMATEL illustrates the degree of influence among key elements as well as the interdependency of relationships between attributes using an influential network relationship map (INRM) based on graph theory [29].

This study proposes a hybrid shared decision-making and multiattribute decision-making model (called SDM-MADM model). First of all, the SDM index system is established on the basis of previous literature review of key elements of SDM. Then, the DEMATEL method calculates the total influence degree among the key elements and shows their influence network relationship map (INRM). Finally, based on INRM, clinicians can understand the influence relationship structure among key elements and identify a few key success factors in SDM. The contributions of this research are as follows: (i) we present an SDM index system based on a review of the literature pertaining to SDM and practical clinical experience; (ii) this study demonstrates the potential of applying MADM methods to the issue of medical management; and (iii) the proposed SDM-MADM model can elucidate for clinicians the factors that are key to the success of SDM in order to facilitate a meaningful exchange with patients.

Empirical data in this study were obtained from actual clinical experience in a major hospital in China. The remainder of this study is organized as follows. Section 2 presents a review of the literature pertaining to SDM. Section 3 presents the proposed SDM-MADM model. Section 4 illustrates the clinical application of the SDM-MADM model in a real-world setting. Conclusions and future research directions are presented in Section 5.

\section{Literature Review}

SDM is an important factor in treatment counselling [30]. Researchers have long sought to develop a core definition of codecision-making and consistent measures related to patient outcomes [31, 32]. The most widely accepted SDM model draws on the work of Charles et al., which outlined a number of key features [33, 34]: (i) the patient and clinician are both involved in the treatment decision-making process, (ii) the patients and clinician share information, (iii) the patient and clinician express treatment preferences, and (iv) the patient and clinician jointly make treatment decisions and agree on follow-up treatment. Subsequent research can be divided into (1) the development and application of SDM scales and (2) key elements/features in the SDM process.
2.1. The Development and Application of SDM Scales. Braddock et al. [17] proposed six key elements of informed decision-making (IDM) for routine practice. Braddock et al. [18] then expanded the IDM model to include seven key elements to explore the nature and integrity of informed decisions made by primary care doctors and surgeons in routine outpatient clinics. Simon et al. [35] compiled and verified a theory-driven questionnaire to assess the shared decision process, referred to as the shared decision-making questionnaire (SDM-Q). Kriston et al. [19] revised the original SDM-Q as a new 9-item instrument referred to as the SDM-Q-9. Kheirkhah et al. [36] applied the SDM-Q-Doc version to explore the psychological predictors of SDM between residents and patients. Based on the SDM-Q-9, Kriston et al. [37] formulated a network model to assess the competency of clinicians in applying SDM and predicting outcomes. Song and Sandra [38] used a 10-item IDM scale to investigate the experience of elderly patients in postdialysis decision-making. Rothberg et al. [39] used a 7-item IDM scale to assess IDM and its correlation with patient decisionmaking. The IDM and SDM scales can be used alone or in combination with other scales to broaden analysis to other issues, such as quality of life.

\subsection{Composition of Key Elements in the SDM Process.} Using content analysis, DuBenske et al. [12] identified 3 key components and 13 corresponding key elements. Makoul and Clayman [31] identified 3 key components and 23 corresponding elements in the SDM process. Legare and Witteman [40] identified 3 key factors in routine clinical practice. Bomhof-Roordink et al. [11] identified 53 elements and classified them within 24 categories. Dy and Purnell [41] conducted a literature review on the key concepts related to SDM in healthcare. The studies above provided a framework to develop SDM index systems in subsequent MADM models.

2.3. Research Gaps. The above research focused on the application of SDM scales and key elements in SDM. The former examined the use of SDM, alone and when implemented with other clinical scales. The latter demonstrated the importance of key elements in SDM; however, there was a failure to identify the factors that are keys to the success of such endeavours. In this study, we used the MADM methodology to overcome this problem.

\section{Methodology}

In this study, we developed an integrated SDM-MADM model, which began with the development of an index system based on a review of the literature pertaining to key elements in SDM. We then applied the DEMATEL method to the proposed index system to establish the structure of influence among key elements.

3.1. The SDM Index System. We began by examining changes in the shared decision-making environment and the views of 
decision-makers over time. Bomhof-Roordink [11] performed a systematic search of SDM-related articles published prior to September 2, 2019, from seven electronic databases (i.e., Academic Search Premier, Cochrane, Embase, Emcare, PsycINFO, PubMed, and Web of Science). From these databases, they identified 53 elements in SDM model descriptions and classified them within 24 components. Note that key elements apply to three types of SDM models: (1) models containing more than half of the components, (2) models focusing on a single actor within components (i.e., healthcare professional), and (3) models in which the components vary over time (without a clear pattern). In the current study, we based our index system on the research of Bomhof-Roordink [11] and corresponding references.

Our primary objective in this study was to explore the interdependent relationships among key elements of SDM and identify the factors that are keys to its success. We created a model covering more than half of the components with top ranking main components (i.e., recurring in research with the highest frequency) as our framework. The top 4 components appeared in more than $60 \%$ of the studies, as follows: "Describe treatment options" (80\%), "Make the decision" (75\%), "Patient preferences" (65\%), and "Tailor information" (65\%). Table 1 lists the references corresponding to the key elements of SDM models.

3.2. The DEMATEL Method. The DEMATEL method was developed by the Battelle Memorial Institute in 1972 to resolve interdependent structure problems in the real world [27]. This graph theory-based method can be used to analyse and solve problems involving relationships of mutual influence via visualization [50,51]. Structural modelling makes it easier for a researcher to understand interdependent relationships among elements in a complex system as well as resolve complex problems based on an understanding of cause-effect relationships. DEMATEL has been applied with considerable success in green supply chain management [52, 53], cultural products [54], shelter sites [55], company performance [56], and water management [57]. The computation steps are outlined in the following [58-60]:

Step 1. Initial influence relation matrix $\mathbf{A}$ based on domain knowledge.

The practical experience of domain experts can be leveraged to establish a direct influence relation matrix, in which the numerical value represents the degree of influence between attribute/element $i$ and attribute/element $j$. Note that the values are derived from a set of 5-value Likert scales (from no influence (0) to very high influence (4)). Direct influence relation matrices are integrated into matrix $\mathbf{A}$ via averaging in order to assess the opinions of a group of experts pertaining to the interactions among attributes, as follows:

$$
\mathbf{A}=\left[a_{i j}\right]_{n \times n}=\left[\frac{\left(\sum_{\eta=1}^{k} e_{i j}^{\eta}\right)}{k}\right]_{n \times n},
$$

where the diagonal values in the matrix are 0 , the other values are between 0 and 4 , and $n$ indicates the total number of attributes/elements in the system.
The level of significant confidence of matrix $\mathbf{A}$ can be obtained using equation (2). Here, the threshold must exceed $95 \%$ (i.e., average ratio gap less than 5\%), where a higher ratio indicates results of higher stability/ confidence.

$$
\frac{1}{n(n-1)} \sum_{i=1}^{k} \sum_{j=1}^{k} \frac{\left|a_{i j}^{k}-a_{i j}^{k-1}\right|}{a_{i j}^{k}} \times 100 \% .
$$

Step 2. Normalized influence relation matrix $\mathbf{B}$ transferred from matrix A.

The range of the influence relationship depicted in matrix $\mathbf{A}$ requires a series of conversion actions to establish the preliminary state of the total influence relationship between attributes/elements. This normalization process is implemented as follows:

$$
\begin{aligned}
& \mathbf{B}=\rho \times \mathbf{A}, \\
& \rho=\min \left\{\frac{1}{\max _{i}} \sum_{j=1}^{n} a_{i j}, \frac{1}{\max _{j}} \sum_{i=1}^{n} a_{i j}\right\}, \quad i, j \in\{1,2, \ldots, n\},
\end{aligned}
$$

where $\rho$ is the adjustment coefficient, and the maximum value of the sum of rows or columns of matrix $\mathbf{B}$ is 1 .

Step 3. Total influence relation matrix $\mathbf{O}$ calculated from matrix.

In accordance with the Markov chain, the total influence degree (direct, indirect, and subsequent influences) between attributes/elements can be estimated under the condition of matrix $\mathbf{B}$. Total influence relation matrix $\mathbf{O}$ is derived as follows:

$$
\begin{aligned}
\mathbf{O} & =\mathbf{B}+\mathbf{B}^{2}+\mathbf{B}^{3}+\cdots+\mathbf{B}^{\tau} \\
& =\mathbf{B}\left(\mathbf{I}+\mathbf{B}+\mathbf{B}^{2}+\cdots+\mathbf{B}^{\tau-1}\right)\left[(\mathbf{I}-\mathbf{B})(\mathbf{I}-\mathbf{B})^{-1}\right] \\
& =\mathbf{B}\left(\mathbf{I}-\mathbf{B}^{\tau}\right)(\mathbf{I}-\mathbf{B})^{-1} \\
& =\mathbf{B}(\mathbf{I}-\mathbf{B})^{-1)}, \quad \text { when } \tau \longrightarrow \infty, \mathbf{B}^{\tau}=[0]_{n \times n},
\end{aligned}
$$

where matrix I refers to the identity matrix.

Step 4. Influence network relationship map (INRM).

This map is used to visualize the net mutual influence among attributes in order to identify key elements and elucidate the means by which they interact. First, four indices are extended from matrix $\mathbf{O}$ as main components of the network diagram: "influence given $\left(r_{i}\right)$," "influence received $\left(u_{i}\right)$," "prominence/centrality $\left(r_{i}+u_{i}\right)$," and "relation/causal effect $\left(r_{i}-u_{i}\right)$," such as equations (6)-(9). In constructing the space of the network diagram, prominence/centrality $\left(r_{i}+u_{i}\right)$ and the relation/causal-effect $\left(r_{i}-u_{i}\right)$ are, respectively, listed along the $x$-axis and $y$-axis. Finally, the direction of the main influence between attributes/elements 
TABLE 1: Key elements of the shared decision-making model.

\begin{tabular}{|c|c|c|c|}
\hline Aspect & Attribute & Description & Ref \\
\hline \multirow{4}{*}{$\begin{array}{l}\text { Describe treatment } \\
\text { options }\left(C_{1}\right)\end{array}$} & Benefits/risk $\left(C_{11}\right)$ & $\begin{array}{l}\text { Doctors and patients should discuss the advantages and } \\
\text { disadvantages of the proposed treatment options because } \\
\text { they may have different views on the relative importance } \\
\text { of the benefits, disadvantages, risks, and costs of } \\
\text { treatment. }\end{array}$ & {$[11,31,42-44]$} \\
\hline & Feasibility of options $\left(C_{12}\right)$ & $\begin{array}{c}\text { Doctors and patients should review the feasibility of } \\
\text { treatment options based on a variety of reference } \\
\text { information, including the patient's physical condition, } \\
\text { treatment methods, and costs. }\end{array}$ & {$[11,31,45]$} \\
\hline & List options $\left(C_{13}\right)$ & $\begin{array}{l}\text { Doctors should make a clear list of treatment options } \\
\text { based on medical and clinical knowledge. Patients should } \\
\text { also propose other treatment options of which they may } \\
\text { know. }\end{array}$ & {$[4,5,11,31,44,46]$} \\
\hline & Present evidence $\left(C_{14}\right)$ & $\begin{array}{l}\text { Doctors should base decisions on existing medical } \\
\text { evidence. }\end{array}$ & {$[11,31]$} \\
\hline
\end{tabular}

It is important to record the issues and decisions related to Document (discussion the treatment options discussed by doctors and patients, about) decision $\left(C_{21}\right) \quad$ including patient concerns, preferences, and information needs as well as treatment and nursing methods.

Patients do not always make decisions when they first discuss problems, postponing them to a later time (e.g., $\begin{array}{ccc}\text { Make the decision } & \begin{array}{c}\text { Make or explicitly defer } \\ \text { decision }\left(C_{22}\right)\end{array} & \text { waiting for discussions with families and/or medical team } \\ \text { members). Doctors and patients should therefore arrange }\end{array}$ $\left(C_{2}\right)$

follow-up visits to track outstanding decisions and reach a resolution.

Patient retains ultimate Patients should maintain decision-making power authority over decision $\left(C_{23}\right)$ pertaining to final treatment options.

In cases where the available treatment options cannot Revisiting decision $\left(C_{24}\right) \quad$ produce the expected health results, the patient may reconsider the decision.

\begin{tabular}{|c|c|c|c|}
\hline \multirow{3}{*}{$\begin{array}{l}\text { Patient preferences } \\
\left(C_{3}\right)\end{array}$} & Patient concerns $\left(C_{31}\right)$ & $\begin{array}{l}\text { Clinicians should consider the concerns (fears) of patients } \\
\text { pertaining to treatment options, including postoperative } \\
\text { recovery, quality of life, and medical expenses. }\end{array}$ & {$[11,21,32]$} \\
\hline & Patient goals of care $\left(C_{32}\right)$ & $\begin{array}{l}\text { Clinicians should consider the expectations of patients in } \\
\text { terms of nursing objectives (preoperative and } \\
\text { postoperative). }\end{array}$ & {$[4,11,21]$} \\
\hline & $\begin{array}{l}\text { Patient values and } \\
\text { preferences }\left(C_{33}\right)\end{array}$ & $\begin{array}{l}\text { Clinicians should consider the values of patients (e.g., } \\
\text { outlook on life, concepts, spirit, and culture). }\end{array}$ & {$[4,11,21,31]$} \\
\hline \multirow{4}{*}{$\begin{array}{l}\text { Tailor information } \\
\left(C_{4}\right)\end{array}$} & $\begin{array}{l}\text { Ascertain preferred } \\
\text { information }\left(C_{41}\right)\end{array}$ & $\begin{array}{c}\text { Clinicians should provide patients with all important } \\
\text { information. }\end{array}$ & {$[11,47]$} \\
\hline & $\begin{array}{l}\text { Check understanding } \\
\text { patient }\left(C_{42}\right)\end{array}$ & $\begin{array}{l}\text { Clinicians should confirm the overall situation of the } \\
\text { patient, including illness, concerns, and preferences. }\end{array}$ & {$[11,31,44,47]$} \\
\hline & Flexibility approach $\left(C_{43}\right)$ & $\begin{array}{l}\text { As situations change, doctors and patients should be } \\
\text { prepared to reconsider their decision(s). The decision- } \\
\text { making process must remain flexible. }\end{array}$ & {$[11,31]$} \\
\hline & Use clear language $\left(C_{44}\right)$ & $\begin{array}{c}\text { Clinicians should use simple language in the provision of } \\
\text { information to patients. }\end{array}$ & {$[5,11,49]$} \\
\hline
\end{tabular}

is adopted as the net influence relationship for subsequent evaluations.

Influence given is

$$
r_{i}=\left(r_{i}\right)_{n \times 1}=\left(r_{1}, \ldots, r_{i}, \ldots, r_{n}\right)=\left[\sum_{j=1}^{n} o_{i j}\right]_{n \times 1} .
$$

Influence received is $u_{i}=\left(u_{i}\right)_{n \times 1}=\left(u_{j}\right)_{1 \times n}{ }^{\prime}=\left(u_{1}, \ldots, u_{j}, \ldots, u_{n}\right)^{\prime}=\left[\sum_{i=1}^{n} o_{i j}\right]_{1 \times n}$.

Prominence/centrality is

$$
r_{i}+u_{i}, \quad i \in\{1,2, \ldots, n\}
$$

Relation/causal effect is 


$$
r_{i}-u_{i}, \quad i \in\{1,2, \ldots, n\} .
$$

where $I$ represents the transposed action; $r_{i}$ represents the total impact of attributes/elements on other attributes/elements (including itself) within the system; $u_{i}$ represents the total impact of attributes/elements affected by other attributes/elements (including itself) within the system; $r_{i}+u_{i}$ indicates the influence strength of attributes/elements in the system, where a higher value indicates higher correlation between itself and all other attributes; and $r_{i}-u_{i}$ indicates the net influence of attributes/elements in the system. The values can be divided into three scenarios: (1) values exceeding 0 mainly affect other attributes/elements and may be included in the reason group; (2) values lower than 0 are affected mainly by other attributes/elements and may be included in the results group; and (3) values close to 0 do not have a significant net influence.

\section{Empirical Case Study, Results, and Discussion}

In this section, we illustrate an SDM-MADM model based on the experience of 11 clinicians. We also identify the most influential factors and discuss the degree to which these insights many inform management decisions.

\subsection{Background Description and Data Sources. The hospital} in this case study was a three-level brain hospital overseen by the Shanghai Municipal Health Committee. In establishing this hospital, administrators sought to build a "Chinese Mayo Clinic." At this hospital, the process of diagnosis and treatment begins with clinicians seeking to gain a comprehensive understanding of a patient's condition and economic situation. They accordingly draw up a suitable medical plan and recommendations for the patient. Finally, clinicians and patients jointly formulate a final medical plan. Essentially, shared decision-making is used as the basis of clinical decision-making within the context of patient concerns and preferences. Discussions between the two sides are meant to reduce information asymmetry in the decision-making process. For these reasons, the concept and management mode of case hospital is very suitable as a demonstration case for this study.

There are 11 domain experts in this study, all of whom had more than 10-15 years of practical clinical experience as attending doctors $(n=5)$ and director physicians $(n=6)$. As outlined above, a 5-point Likert scale (no influence (0) to very high influence (4)) is routinely used to transform clinical experience into a direct influence relation matrix. The 11 direct influence relation matrices were integrated into a matrix $\mathbf{A}$ via averaging to create the initial direct influence relation matrix, as shown in Table 2 . The confidence level of the matrix was $97.41 \%$ (i.e., average rat).

4.2. Influence Structure among Attributes. Using equations (3) and (4), initial influence relation matrix $\mathbf{A}$ was converted into normalized influence relation matrix $\mathbf{B}$ with values between 0 and 1 . Using equation (5), the total influence degree between attributes was calculated to obtain total influence relation matrix $\mathbf{O}$ (Table 3 ).

Using equations (6)-(9), we then identified the 4 influential indicators for each attribute (Table 4). The top attributes of the aspect level in the prominence/centrality $\left(r_{i}+u_{i}\right)$ index were ranked from high to low as follows: make the decision $\left(C_{2}\right)>$ describe treatment options $\left(C_{1}\right) \succ$ patient preferences $\left(C_{3}\right)>$ tailor information $\left(C_{4}\right)$. The top attributes in the relation/causal effect $\left(r_{i}-u_{i}\right)$ were ranked from high to low as follows: tailor information $\left(C_{4}\right)>$ patient preferences $\left(C_{3}\right)>$ describe treatment options $\left(C_{1}\right)>$ make the decision $\left(C_{2}\right)$. At the attribute level, the top attributes in the prominence/centrality $\left(r_{i}+u_{i}\right)$ were ranked from high to low as follows: patient retains ultimate authority over decision $\left(C_{23}\right)>$ patient concerns $\left(C_{31}\right)>$ make or explicitly defer decision $\left(C_{22}\right)$. The top attribute in the relation/causal effect $\left(r_{i}-u_{i}\right)$ was patient values and preferences $\left(C_{33}\right)$.

Based on prominence/centrality $\left(r_{i}+u_{i}\right)$ and the relation/ causal effect $\left(r_{i}-u_{i}\right)$ in Table 4 , we established an influence network-relation map (INRM) of the SDM index system, as shown in Figure 1. Aspect analysis (Figure 1) identified tailor information $\left(C_{4}\right)$ as the most important aspect based on to its effects on patient preferences $\left(C_{3}\right)$, describe treatment options $\left(C_{1}\right)$, and make the decision $\left(C_{2}\right)$. This means that when communicating with patients, clinicians should seek to tailor information specifically to the needs of the patient. When we looked more closely at the issue of tailor information $\left(C_{4}\right)$, we found that the most important attribute was check understanding patient $\left(C_{42}\right)$. Intuitively, this appears correct as it helps to ensure that clinicians explain procedures using simple language. The most important attributes under patient preferences $\left(C_{3}\right)$ were patient values and preferences $\left(C_{33}\right)$. Naturally, considering the values and preferences of patients is the only way to allay their concerns. The most important attribute under describe treatment options $\left(C_{1}\right)$ was present evidence $\left(C_{14}\right)$. Obviously, treatment options must be based on practical clinical research and evidence. The most important attribute under make the decision $\left(C_{2}\right)$ was make or explicitly defer decision $\left(C_{22}\right)$. Generally, patients feel the need to confer with friends and family before making important medical decisions. Note also that patients are expected to make the final decisions.

4.3. Analysis and Discussion. Check understanding patient $\left(C_{42}\right)$, patient values and preferences $\left(C_{33}\right)$, make or explicitly defer decision $\left(C_{22}\right)$, and present evidence $\left(C_{14}\right)$ were identified as the most influential factors. These may also be regarded as the key factors determining success in overcoming information asymmetry via joint decision-making. SDM is meant to be used by clinicians and patients jointly when making medical decisions. It is based on the sharing of information for which evidence exists in order to satisfy the needs of the patient based on their values and preferences $[3-5,61]$. Thus, the first task in SDM is to ensure that patients make decisions with a full understanding of key issues, rather than in the face of avoidable ignorance [62]. 
TABLe 2: Initial influence relation matrix A.

\begin{tabular}{|c|c|c|c|c|c|c|c|c|c|c|c|c|c|c|c|}
\hline & $C_{11}$ & $C_{12}$ & $C_{13}$ & $C_{14}$ & $C_{21}$ & $C_{22}$ & $C_{23}$ & $C_{24}$ & $C_{31}$ & $C_{32}$ & $C_{33}$ & $C_{41}$ & $C_{42}$ & $C_{43}$ & $C_{44}$ \\
\hline$C_{11}$ & 0.00 & 3.18 & 1.82 & 2.00 & 2.36 & 2.64 & 2.45 & 2.82 & 2.45 & 2.55 & 1.27 & 2.09 & 2.00 & 1.55 & 1.82 \\
\hline$C_{12}$ & 3.00 & 0.00 & 2.27 & 2.91 & 2.45 & 2.36 & 2.91 & 2.64 & 2.82 & 2.45 & 1.91 & 2.00 & 1.82 & 1.82 & 2.00 \\
\hline$C_{13}$ & 2.45 & 2.27 & 0.00 & 2.18 & 2.45 & 2.27 & 2.73 & 2.82 & 2.27 & 2.18 & 1.91 & 2.18 & 1.82 & 1.73 & 1.91 \\
\hline$C_{14}$ & 2.73 & 3.18 & 2.27 & 0.00 & 2.91 & 2.73 & 2.82 & 2.73 & 2.55 & 2.09 & 1.82 & 2.27 & 1.55 & 1.91 & 2.00 \\
\hline$C_{21}$ & 2.73 & 2.64 & 2.73 & 2.91 & 0.00 & 2.73 & 2.64 & 2.73 & 2.55 & 2.18 & 1.82 & 2.64 & 1.55 & 2.00 & 2.18 \\
\hline$C_{22}$ & 3.00 & 3.09 & 3.09 & 2.55 & 2.82 & 0.00 & 2.64 & 2.82 & 2.64 & 2.27 & 1.73 & 2.18 & 1.82 & 1.82 & 2.00 \\
\hline$C_{23}$ & 2.55 & 3.00 & 2.82 & 2.18 & 3.18 & 2.55 & 0.00 & 2.73 & 2.45 & 2.55 & 2.00 & 2.55 & 2.09 & 2.00 & 2.36 \\
\hline$C_{24}$ & 2.27 & 2.55 & 2.45 & 2.45 & 2.36 & 2.64 & 2.64 & 0.00 & 2.27 & 2.36 & 1.55 & 2.45 & 1.91 & 1.91 & 2.18 \\
\hline$C_{31}$ & 2.55 & 2.55 & 2.64 & 2.45 & 2.18 & 2.64 & 2.82 & 2.55 & 0.00 & 2.73 & 2.55 & 2.36 & 2.36 & 1.91 & 2.36 \\
\hline$C_{32}$ & 2.18 & 2.64 & 2.18 & 2.09 & 2.36 & 2.64 & 3.00 & 2.55 & 2.55 & 0.00 & 1.73 & 2.09 & 2.09 & 1.64 & 2.00 \\
\hline$C_{33}$ & 2.00 & 2.27 & 2.09 & 1.91 & 2.18 & 2.45 & 2.64 & 2.36 & 2.82 & 2.73 & 0.00 & 2.00 & 2.45 & 2.00 & 2.36 \\
\hline$C_{41}$ & 2.36 & 2.36 & 2.45 & 2.64 & 2.64 & 2.82 & 2.82 & 2.73 & 3.00 & 2.45 & 2.36 & 0.00 & 2.09 & 2.27 & 2.55 \\
\hline$C_{42}$ & 2.00 & 2.36 & 2.64 & 2.18 & 2.73 & 2.45 & 2.36 & 2.45 & 2.36 & 2.18 & 2.27 & 2.18 & 0.00 & 2.27 & 2.27 \\
\hline$C_{43}$ & 2.00 & 2.18 & 2.27 & 1.82 & 2.45 & 2.18 & 2.45 & 2.64 & 2.55 & 2.18 & 1.82 & 2.27 & 2.00 & 0.00 & 2.18 \\
\hline$C_{44}$ & 1.82 & 2.18 & 2.36 & 2.00 & 2.45 & 2.55 & 2.73 & 2.73 & 2.82 & 2.36 & 2.27 & 2.55 & 2.18 & 2.00 & 0.00 \\
\hline
\end{tabular}

Note: the value is obtained by equation (1), and the significant confidence level of the matrix is $97.41 \%$ (i.e., average ratio gap is $2.59 \%$ ).

TABLE 3: Total influence relation matrix $\mathbf{O}$.

\begin{tabular}{lcccccccccccccccc}
\hline & $C_{11}$ & $C_{12}$ & $C_{13}$ & $C_{14}$ & $C_{21}$ & $C_{22}$ & $C_{23}$ & $C_{24}$ & $C_{31}$ & $C_{32}$ & $C_{33}$ & $C_{41}$ & $C_{42}$ & $C_{43}$ & $C_{44}$ \\
\hline$C_{11}$ & 0.42 & 0.52 & 0.46 & 0.45 & 0.49 & 0.50 & 0.52 & 0.52 & 0.50 & 0.47 & 0.37 & 0.44 & 0.39 & 0.37 & 0.42 \\
$C_{12}$ & 0.52 & 0.48 & 0.50 & 0.50 & 0.53 & 0.52 & 0.56 & 0.55 & 0.54 & 0.50 & 0.40 & 0.47 & 0.41 & 0.40 & 0.45 \\
$C_{13}$ & 0.48 & 0.51 & 0.42 & 0.46 & 0.50 & 0.49 & 0.53 & 0.52 & 0.50 & 0.46 & 0.38 & 0.45 & 0.39 & 0.38 & 0.42 \\
$C_{14}$ & 0.52 & 0.56 & 0.51 & 0.43 & 0.54 & 0.54 & 0.56 & 0.56 & 0.53 & 0.49 & 0.40 & 0.48 & 0.41 & 0.40 & 0.45 \\
$C_{21}$ & 0.52 & 0.55 & 0.52 & 0.51 & 0.47 & 0.54 & 0.56 & 0.56 & 0.54 & 0.50 & 0.41 & 0.49 & 0.41 & 0.41 & 0.46 \\
$C_{22}$ & 0.53 & 0.57 & 0.54 & 0.50 & 0.55 & 0.48 & 0.57 & 0.57 & 0.55 & 0.51 & 0.41 & 0.49 & 0.42 & 0.41 & 0.46 \\
$C_{23}$ & 0.53 & 0.57 & 0.54 & 0.50 & 0.56 & 0.55 & 0.51 & 0.57 & 0.55 & 0.52 & 0.42 & 0.50 & 0.43 & 0.42 & 0.47 \\
$C_{24}$ & 0.48 & 0.52 & 0.49 & 0.47 & 0.51 & 0.51 & 0.54 & 0.47 & 0.51 & 0.48 & 0.38 & 0.46 & 0.40 & 0.39 & 0.44 \\
$C_{31}$ & 0.52 & 0.56 & 0.53 & 0.50 & 0.54 & 0.55 & 0.58 & 0.57 & 0.49 & 0.52 & 0.43 & 0.49 & 0.44 & 0.41 & 0.47 \\
$C_{32}$ & 0.48 & 0.52 & 0.48 & 0.46 & 0.50 & 0.51 & 0.54 & 0.53 & 0.51 & 0.42 & 0.38 & 0.45 & 0.40 & 0.38 & 0.43 \\
$C_{33}$ & 0.48 & 0.52 & 0.49 & 0.46 & 0.50 & 0.51 & 0.54 & 0.53 & 0.52 & 0.49 & 0.35 & 0.46 & 0.42 & 0.39 & 0.44 \\
$C_{41}$ & 0.53 & 0.57 & 0.54 & 0.52 & 0.56 & 0.56 & 0.59 & 0.58 & 0.57 & 0.52 & 0.44 & 0.44 & 0.44 & 0.43 & 0.48 \\
$C_{42}$ & 0.49 & 0.53 & 0.50 & 0.47 & 0.52 & 0.52 & 0.54 & 0.54 & 0.52 & 0.48 & 0.41 & 0.47 & 0.36 & 0.40 & 0.45 \\
$C_{43}$ & 0.46 & 0.50 & 0.47 & 0.44 & 0.49 & 0.49 & 0.52 & 0.52 & 0.50 & 0.46 & 0.38 & 0.45 & 0.39 & 0.33 & 0.42 \\
$C_{44}$ & 0.49 & 0.53 & 0.50 & 0.47 & 0.52 & 0.52 & 0.55 & 0.55 & 0.53 & 0.49 & 0.41 & 0.48 & 0.42 & 0.40 & 0.39 \\
\hline
\end{tabular}

Note: the value is obtained by equations (3)-(5).

TABLE 4: The four influence indicators for each attribute/element.

\begin{tabular}{|c|c|c|c|c|c|c|c|c|c|}
\hline & $r_{i}$ & $u_{i}$ & $r_{i}+u_{i}$ & $r_{i}-u_{i}$ & & $r_{i}$ & $u_{i}$ & $r_{i}+u_{i}$ & $r_{i}-u_{i}$ \\
\hline \multirow[t]{4}{*}{$C_{1}$} & $1.891(4)$ & $2.006(2)$ & $3.897(2)$ & $-0.115(3)$ & $C_{11}$ & $6.844(14)$ & $7.444(8)$ & $14.288(11)$ & $-0.601(12)$ \\
\hline & & & & & $C_{12}$ & $7.323(7)$ & 8.003 & $15.326(4)$ & $-0.679(14)$ \\
\hline & & & & & $C_{13}$ & $6.873(13)$ & $7.497(7)$ & $14.370(9)$ & $-0.624(13)$ \\
\hline & & & & & $C_{14}$ & $7.370(6)$ & $7.148(10)$ & $14.519(8)$ & $0.222(6)$ \\
\hline \multirow[t]{4}{*}{$\overline{C_{2}}$} & $1.977(1)$ & $2.128(1)$ & $4.105(1)$ & $-0.151(4)$ & $C_{21}$ & $7.459(5)$ & $7.780(6)$ & $15.239(5)$ & $-0.320(10)$ \\
\hline & & & & & $C_{22}$ & $7.542(4)$ & $7.799(5)$ & $15.341(3)$ & $-0.258(7)$ \\
\hline & & & & & $C_{23}$ & $7.659(2)$ & $8.210(1)$ & $15.870(1)$ & $-0.551(11)$ \\
\hline & & & & & $C_{24}$ & $7.049(11)$ & $8.135(2)$ & $15.184(6)$ & $-1.086(15)$ \\
\hline \multirow[t]{3}{*}{$\overline{C_{3}}$} & $1.920(3)$ & $1.875(3)$ & $3.796(3)$ & $0.045(2)$ & $C_{31}$ & $7.581(3)$ & $7.862(4)$ & $15.443(2)$ & $-0.281(8)$ \\
\hline & & & & & $C_{32}$ & $6.998(12)$ & $7.305(9)$ & $14.302(10)$ & $-0.307(9)$ \\
\hline & & & & & $C_{33}$ & $7.099(10)$ & $5.969(14)$ & $13.068(14)$ & $1.129(1)$ \\
\hline \multirow[t]{4}{*}{$\overline{C_{4}}$} & $1.935(2)$ & $1.714(4)$ & $3.650(4)$ & $0.221(1)$ & $C_{41}$ & $7.780(1)$ & $7.012(11)$ & $14.792(7)$ & $0.767(4)$ \\
\hline & & & & & $C_{42}$ & $7.187(9)$ & $6.118(13)$ & $13.306(13)$ & $1.069(2)$ \\
\hline & & & & & $C_{43}$ & $6.834(15)$ & $5.930(15)$ & $12.764(15)$ & $0.904(3)$ \\
\hline & & & & & $C_{44}$ & $7.259(8)$ & $6.644(12)$ & $13.903(12)$ & $0.615(5)$ \\
\hline
\end{tabular}

Note: the value is obtained by equations (6)-(9), and the value in () is ranking. 


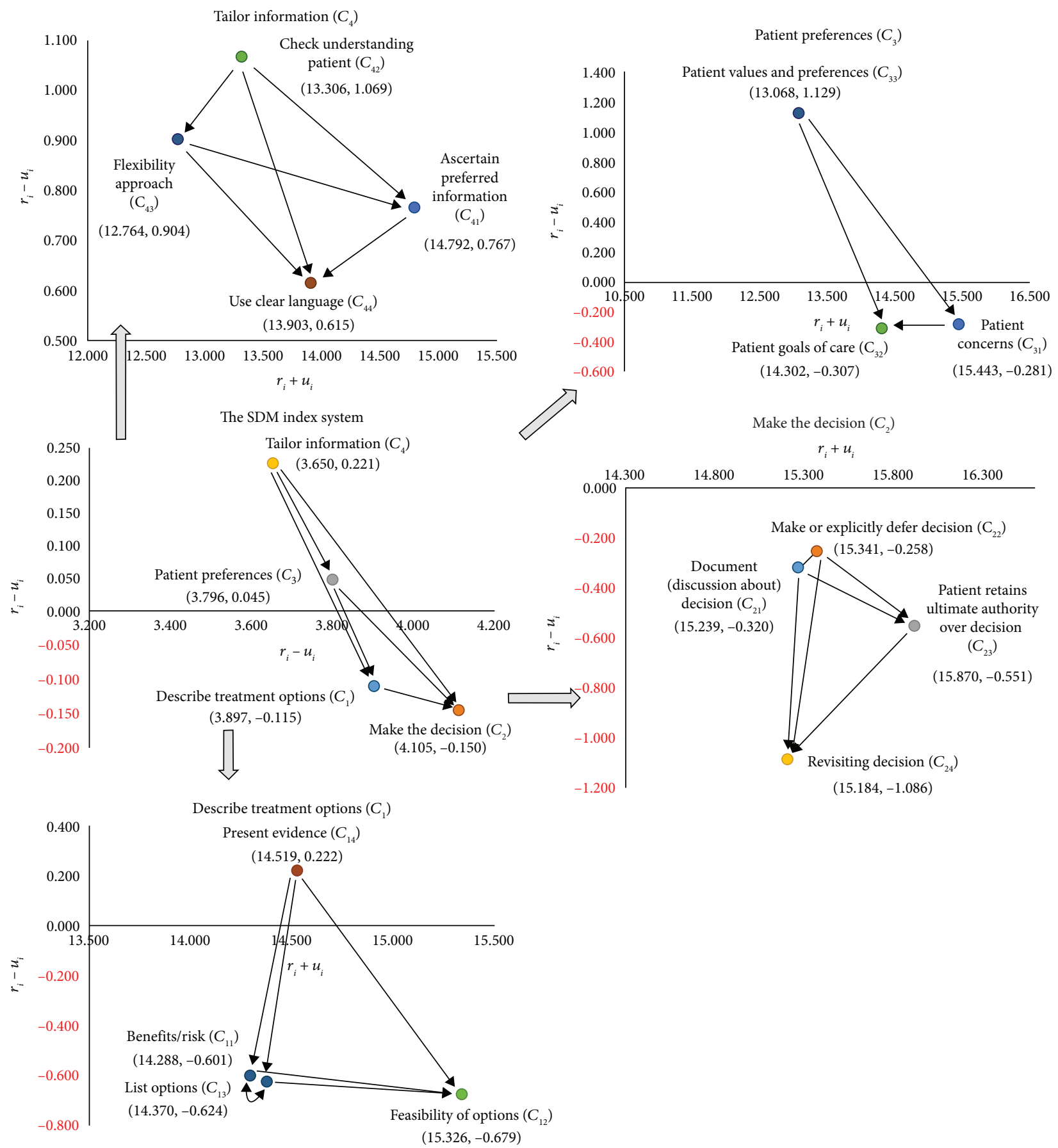

FIGURE 1: Influential network-relation map (INRM).

One randomized trial study revealed that patients who possessed more knowledge were more confident in making decisions [63]. Only when clinicians make an effort to confirm that patients fully comprehend all of the information that they have received can patients then make informed treatment decisions [64]. From the perspective of clinical management, SDM should focus on communication between clinicians and patients through a patient-centred exchange of information. Clinicians should strive to explain all options, advantages, and disadvantages of any given treatment plan as well as the subsequent nursing plan.
Likewise, patients and their families should feel free to outline their concerns, values, and preferences to facilitate the establishment of further options in line with their wishes and expectations. Finally, clinicians should learn to bestow information using simple language and clear illustrations.

\section{Conclusions}

SDM aimed at reducing information asymmetry between clinicians and patients should be based on clinical evidence 
within the context of patient preferences. In this study, we employed the DEMATEL technique to construct a network of influential relationships among key elements pertaining to SDM. Our analysis revealed four issues that are crucial to the success of all such endeavours: check understanding patient $\left(C_{42}\right)$, patient values and preferences $\left(C_{33}\right)$, make or explicitly defer decision $\left(C_{22}\right)$, and present evidence $\left(C_{14}\right)$. Clinicians should seek to consider the concerns and preferences of patients in the presentation of medical options and follow-up care plans. Clinicians should also strive to ensure that the patient fully comprehends the entire treatment process as well as its advantages and disadvantages. At the same time, patients should be encouraged to express their concerns and thoughts and feel free to ask questions. Different clinical conditions may have different results, so the results of this study are limited to the experience of the hospital in this case. In addition, this study does not consider various ambiguities in the decision-making environment. The future MADM model can be combined with fuzzy theory or the grey system to discuss the shared decisionmaking problem more deeply.

\section{Data Availability}

The data used to support the findings of this study are included within the article.

\section{Conflicts of Interest}

The authors declare that they have no conflicts of interest.

\section{Authors' Contributions}

Wen-Yi Liu and Tao-Hsin Tung contributed equally in this study.

\section{Acknowledgments}

The authors are very grateful to the brain doctors of the case hospital for assisting in the questionnaire investigation and the reviewers for their valuable opinions.

\section{References}

[1] T. Treffers and P. M. Putora, "Emotions as social information in shared decision-making in oncology," Oncology, vol. 98, pp. 430-437, 2020.

[2] N. Singh Ospina, F. J. K. Toloza, F. Barrera, C. L. Bylund, P. J. Erwin, and V. Montori, "Educational programs to teach shared decision making to medical trainees: a systematic review," Patient Education and Counseling, vol. 103, pp. 1082-1094, 2020.

[3] F. Legare, D. Stacey, S. Pouliot et al., "Interprofessionalism and shared decision-making in primary care: a stepwise approach towards a new model," Journal of Interprofessional Care, vol. 25, pp. 18-25, 2011.

[4] M. H. van de Pol, C. R. Fluit, J. Lagro, Y. H. Slaats, M. G. Olde Rikkert, and A. L. Lagro-Janssen, "Expert and patient consensus on a dynamic model for shared decision-making in frail older patients," Patient Education and Counseling, vol. 99, pp. 1069-1077, 2016.
[5] A. Waschwill, A. Bittner, and S. Harendza, "Assessment of medical students' shared decision-making skills in simulated physician-patient encounters," Patient Education and Counseling, vol. 103, pp. 500-504, 2020.

[6] M. Tai-Seale, G. Elwyn, C. J. Wilson et al., "Enhancing shared decision making through carefully designed interventions that target patient and provider behavior," Health Affairs, vol. 35, pp. 605-612, 2016.

[7] M. A. Stewart, "Effective physician-patient communication and health outcomes: a review," Canadian Medical Association Journal, vol. 152, pp. 1423-1433, 1995.

[8] E. A. Joosten, L. DeFuentes-Merillas, G. H. de Weert, T. Sensky, C. P. van der Staak, and C. A. de Jong, "Systematic review of the effects of shared decision-making on patient satisfaction, treatment adherence and health status," Psychotherapy and Psychosomatics, vol. 77, pp. 219-226, 2008.

[9] C. Rathert, M. D. Wyrwich, and S. A. Boren, "Patient-centered care and outcomes: a systematic review of the literature," Medical Care Research and Review, vol. 70, pp. 351-379, 2013.

[10] L. A. Shay and J. E. Lafata, "Where is the evidence? a systematic review of shared decision making and patient outcomes," Medical Decision Making, vol. 35, pp. 114-131, 2015.

[11] H. Bomhof-Roordink, F. R. Gartner, A. M. Stiggelbout, and A. H. Pieterse, "Key components of shared decision making models: a systematic review," BMJ Open, vol. 9, Article ID e031763, 2019.

[12] L. L. DuBenske, S. B. Schrager, M. E. Hitchcock et al., "Key elements of mammography shared decision-making: a scoping review of the literature," Journal of General Internal Medicine, vol. 33, pp. 1805-1814, 2018.

[13] G. Darien, C. Wilson, A. Balch, and A. Rebekah, "Talking about the cost of care: a critical component of shared decision making: patient and provider perspectives," Journal of the National Medical Association, vol. 112, pp. 225-228, 2020.

[14] L. Boland, I. D. Graham, F. Legare et al., "Barriers and facilitators of pediatric shared decision-making: a systematic review," Implementation Science, vol. 14, p. 7, 2019.

[15] K. Gravel, F. Legare, and I. D. Graham, "Barriers and facilitators to implementing shared decision-making in clinical practice: a systematic review of health professionals' perceptions," Implementation Science, vol. 1, p. 16, 2006.

[16] F. Legare, S. Ratte, K. Gravel, and I. D. Graham, "Barriers and facilitators to implementing shared decision-making in clinical practice: update of a systematic review of health professionals' perceptions," Patient Education and Counseling, vol. 73, pp. 526-535, 2008.

[17] C. H. Braddock 3rd, S. D. Fihn, W. Levinson, A. R. Jonsen, and R. A. Pearlman, "How doctors and patients discuss routine clinical decisions. Informed decision making in the outpatient setting," Journal of General Internal Medicine, vol. 12, pp. 339-345, 1997.

[18] C. H. Braddock 3rd, K. A. Edwards, N. M. Hasenberg, T. L. Laidley, and W. Levinson, "Informed decision making in outpatient practice: time to get back to basics," Journal of the American Medical Association, vol. 282, pp. 2313-2320, 1999.

[19] L. Kriston, I. Scholl, L. Holzel, D. Simon, A. Loh, and M. Harter, "The 9-item Shared Decision Making Questionnaire (SDM-Q-9). Development and psychometric properties in a primary care sample," Patient Education and Counseling, vol. 80, pp. 94-99, 2010.

[20] E. M. Driever, A. M. Stiggelbout, and P. L. P. Brand, "Shared decision making: physicians' preferred role, usual role and 
their perception of its key components," Patient Education and Counseling, vol. 103, pp. 77-82, 2020.

[21] G. Elwyn, M. Tsulukidze, A. Edwards, F. Legare, and R. Newcombe, 'Using a 'talk' model of shared decision making to propose an observation-based measure: observer OPTION 5 Item," Patient Education and Counseling, vol. 93, pp. 265-271, 2013.

[22] J. G. Dolan, "Shared decision-making--transferring research into practice: the analytic hierarchy process (AHP)," Patient Education and Counseling, vol. 73, pp. 418-425, 2008.

[23] J. G. Dolan, E. Boohaker, J. Allison, and T. F. Imperiale, "Can streamlined multicriteria decision analysis be used to implement shared decision making for colorectal cancer screening?," Medical Decision Making, vol. 34, pp. 746-755, 2014.

[24] Y.-C. Chuang, S.-K. Hu, J. J. H. Liou, and H.-W. Lo, "Building a decision dashboard for improving green supply chain management," International Journal of Information Technology \& Decision Making, vol. 17, pp. 1363-1398, 2018.

[25] S. S. Weng, Y. Liu, and Y. C. Chuang, "Reform of Chinese universities in the context of sustainable development: teacher evaluation and improvement based on hybrid multiple criteria decision-making model," Sustainability, vol. 11, 2019.

[26] A. Vafadarnikjoo, H. B. Ahmadi, B. T. Hazen, and J. J. H. Liou, "Understanding interdependencies among social sustainability evaluation criteria in an emerging economy," Sustainability, vol. 12, 2020.

[27] A. Gabus and E. Fontela, World Problems, an Invitation to Further Thought within the Framework of DEMATEL, Battelle Institute, Geneva Research Center, Geneva, Switzerland, 1972.

[28] W. C. J. Hsu, J. J. H. Liou, and H. W. Lo, "A group decisionmaking approach for exploring trends in the development of the healthcare industry in Taiwan," Decision Support Systems, vol. 141, 2021.

[29] H. W. Lo, J. J. H. Liou, C. N. Huang, Y. C. Chuang, and G. H. Tzeng, "A new soft computing approach for analyzing the influential relationships of critical infrastructures," International Journal of Critical Infrastructure Protection, vol. 28, Article ID 100336, 2020.

[30] A. N. Siriwardena, A. G. Edwards, P. Campion, A. Freeman, and G. Elwyn, "Involve the patient and pass the MRCGP: investigating shared decision making in a consulting skills examination using a validated instrument," British Journal of General Practic, vol. 56, pp. 857-862, 2006.

[31] G. Makoul and M. L. Clayman, "An integrative model of shared decision making in medical encounters," Patient Education and Counseling, vol. 60, pp. 301-312, 2006.

[32] M. C. Weiss and T. J. Peters, "Measuring shared decision making in the consultation: a comparison of the OPTION and Informed Decision Making instruments," Patient Education and Counseling, vol. 70, pp. 79-86, 2008.

[33] C. Charles, A. Gafni, and T. Whelan, "Shared decisionmaking in the medical encounter: what does it mean? (or it takes at least two to tango)," Social Science \& Medicine, vol. 44, pp. 681-692, 1997.

[34] C. Charles, A. Gafni, and T. Whelan, "Decision-making in the physician-patient encounter: revisiting the shared treatment decision-making model," Social Science \& Medicine, vol. 49, pp. 651-661, 1999.

[35] D. Simon, G. Schorr, M. Wirtz et al., "Development and first validation of the shared decision-making questionnaire (SDM-Q)," Patient Education and Counseling, vol. 63, pp. 319-327, 2006.
[36] F. Kheirkhah, R. M. Larijani, M. Faramarzi, M. H. Yadollahpour, and S. Khafri, "Psychological predictors of medical residents' perspectives on shared decision-making with patients: a cross-sectional study," BMC Medical Education, vol. 20, p. 251, 2020.

[37] L. Kriston, P. Hahlweg, M. Harter, and I. Scholl, "A skills network approach to physicians' competence in shared decision making," Health Expectations, vol. 23, pp. 1466-1476, 2020.

[38] M. K. Song and S. E. Ward, "The extent of informed decisionmaking about starting dialysis: does patients' age matter?," Journal of Nephrology, vol. 27, pp. 571-576, 2014.

[39] M. B. Rothberg, S. K. Sivalingam, R. Kleppel, M. Schweiger, B. Hu, and K. R. Sepucha, "Informed decision making for percutaneous coronary intervention for stable coronary disease," JAMA Internal Medicine, vol. 175, pp. 1199-1206, 2015.

[40] F. Legare and H. O. Witteman, "Shared decision making: examining key elements and barriers to adoption into routine clinical practice," Health Affairs, vol. 32, pp. 276-284, 2013.

[41] S. M. Dy and T. S. Purnell, "Key concepts relevant to quality of complex and shared decision-making in health care: a literature review," Social Science \& Medicine, vol. 74, pp. 582-587, 2012.

[42] S. Turcotte, H. Robitaille, L. Blair, and F. Legare, "The actorpartner interdependence model in shared decision-making: an illustrative example of its application to the physicianpatient dyad in primary care consultations," Journal of Clinical Epidemiology, vol. 108, pp. 132-139, 2019.

[43] M. A. Schonberg, M. B. Hamel, R. B. Davis et al., "Development and evaluation of a decision aid on mammography screening for women 75 years and older," JAMA Internal Medicine, vol. 174, pp. 417-424, 2014.

[44] S. Rennke, P. Yuan, B. Monash et al., "The SDM 3 circle model: a literature synthesis and adaptation for shared decision making in the hospital," Journal of Hospital Medicine, vol. 12, pp. 1001-1008, 2017.

[45] F. Legare, D. Stacey, S. Gagnon et al., "Validating a conceptual model for an inter-professional approach to shared decision making: a mixed methods study," Journal of Evaluation in Clinical Practice, vol. 17, pp. 554-564, 2011.

[46] G. Elwyn, A. Edwards, P. Kinnersley, and R. Grol, "Shared decision making and the concept of equipoise: the competences of involving patients in healthcare choices," British Journal of General Practic, vol. 50, pp. 892-897, 2000.

[47] M. Truglio-Londrigan, J. T. Slyer, J. K. Singleton, and P. Worral, "A qualitative systematic review of internal and external influences on shared decision-making in all health care settings," JBI Library of Systematic Reviews, vol. 10, pp. 4633-4646, 2012.

[48] C. Y. Lin, L. Renwick, and K. Lovell, "Patients' perspectives on shared decision making in secondary mental healthcare in Taiwan: a qualitative study," Patient Education and Counseling, vol. 103, pp. 2565-2570, 2020.

[49] E. J. Kim and S. H. Kim, "Simplification improves understanding of informed consent information in clinical trials regardless of health literacy level," Clinical Trials, vol. 12, pp. 232-236, 2015.

[50] E. Fontela and A. Gabus, The DEMATEL Observer, Battelle Geneva Research Center, Geneva, Switzerland, 1976.

[51] C. Bai and J. Sarkis, "A grey-based DEMATEL model for evaluating business process management critical success factors," International Journal of Production Economics, vol. 146, pp. 281-292, 2013.

[52] H. H. Wu and S. Y. Chang, "A case study of using DEMATEL method to identify critical factors in green supply chain 
management," Applied Mathematics and Computation, vol. 256, pp. 394-403, 2015.

[53] Z. Wang, K. Mathiyazhagan, L. Xu, and A. Diabat, "A decision making trial and evaluation laboratory approach to analyze the barriers to Green Supply Chain Management adoption in a food packaging company," Journal of Cleaner Production, vol. 117, pp. 19-28, 2016.

[54] C. T. Lin, C. Lee, S. W. Wang, and Y. H. Chen, "Using the DEMATEL method to explore the critical factors that influence visitors to purchase museum cultural products," Journal of Testing and Evaluation, vol. 46, 2018.

[55] A. Trivedi, "A multi-criteria decision approach based on DEMATEL to assess determinants of shelter site selection in disaster response," International Journal of Disaster Risk Reduction, vol. 31, pp. 722-728, 2018.

[56] E. Yadegaridehkordi, M. Hourmand, M. Nilashi, L. Shuib, A. Ahani, and O. Ibrahim, "Influence of big data adoption on manufacturing companies' performance: an integrated DEMATEL-ANFIS approach," Technological Forecasting and Social Change, vol. 137, pp. 199-210, 2018.

[57] R. X. Nie, Z. P. Tian, J. Q. Wang, H. Y. Zhang, and T. L. Wang, "Water security sustainability evaluation: applying a multistage decision support framework in industrial region," Journal of Cleaner Production, vol. 196, pp. 1681-1704, 2018.

[58] Y. C. Chuang, S. K. Hu, J. J. H. Liou, and G. H. Tzeng, "A datadriven madm model for personnel selection and improvement," Technological and Economic Development of Economy, vol. 26, pp. 751-784, 2020.

[59] J. J. H. Liou, Y. C. Chuang, E. K. Zavadskas, and G. H. Tzeng, "Data-driven hybrid multiple attribute decision-making model for green supplier evaluation and performance improvement," Journal of Cleaner Production, vol. 241, 2019.

[60] R. D. Raut, V. S. Yadav, N. Cheikhrouhou, V. S. Narwane, and B. E. Narkhede, "Big data analytics: implementation challenges in Indian manufacturing supply chains," Computers in Industry, p. 125, 2021.

[61] G. Elwyn, S. Laitner, A. Coulter, E. Walker, P. Watson, and R. Thomson, "Implementing shared decision making in the NHS," BMJ, vol. 341, Article ID c5146, 2010.

[62] G. Elwyn, D. Frosch, R. Thomson et al., "Shared decision making: a model for clinical practice," Journal of General Internal Medicine, vol. 27, pp. 1361-1367, 2012.

[63] A. M. O'Connor, D. Stacey, V. Entwistle et al., "Decision aids for people facing health treatment or screening decisions," Cochrane Database of Systematic Reviews, vol. 12, no. 4, Article ID CD001431, 2003.

[64] A. Schattner, A. Bronstein, and N. Jellin, "Information and shared decision-making are top patients' priorities," $B M C$ Health Services Research, vol. 6, p. 21, 2006. 